\title{
The role of land surface schemes in the regional climate model (RegCM) for seasonal scale simulations over Western Himalaya
}

\author{
PUSHP RAJ TIWARI \\ Centre for Atmospheric Sciences, Indian Institute of Technology Delhi, India \\ Corresponding author; e-mail: pushprajiitd@gmail.com \\ SARAT CHANDRA KAR \\ National Centre for Medium Range Weather Forecasting, Noida, India \\ UMA CHARAN MOHANTY \\ School of Earth Ocean and Climate Sciences, IIT Bhubaneswar, India \\ SAGNIK DEY and PALASH SINHA \\ Centre for Atmospheric Sciences, Indian Institute of Technology Delhi, India \\ P. V. S. RAJU \\ Center of Excellence for Climate Change Research, King Abdulaziz University, Saudi Arabia \\ M. S. SHEKHAR \\ Snow and Avalanche Study Establishment, Chandigarh, India
}

Received February 15, 2014; accepted March 10, 2015

\begin{abstract}
RESUMEN
La predicción del clima en el Himalaya occidental es una tarea compleja debido a la gran variabilidad de las barreras orográficas en cuanto a altitud y orientación. Las características de la superficie también desempeñan un papel importante en las simulaciones climáticas, y requieren una representación adecuada en los modelos. En este estudio se utilizaron dos esquemas de parametrización de la superficie terrestre (LSPS, por sus siglas en inglés) para analizar la precipitación estacional en la región del Himalaya: el esquema de transferencia biosfera-atmósfera (BATS, por sus siglas en inglés) y el modelo común de la tierra (CLM, por sus siglas en inglés), v. 3.5, acoplados con el modelo regional del clima RegCM, v. 4. El análisis abarca nueve estaciones invernales diferentes (tres con precipitación excesiva, tres con precipitación normal y tres con déficit de precipitación). Los datos del reanálisis II de los Centros Nacionales de Predicción Ambiental (National Centers for Environmental Prediction, NCEP) del departamento de energía estadounidense se utilizaron como condiciones iniciales y limítrofes para el modelo RegCM. Para aportar condiciones superficiales limítrofes al modelo RegCM se utilizaron parámetros geofísicos similares (resolución de $10 \mathrm{~min}$ ) a los del Mapa Geofísico de Estados Unidos. Se evalúa el desempeño de dos LSPS (CLM y BATS) acoplados con el RegCM en comparación con datos de temperatura superficial y de una malla de precipitación de la Oficina de Meteorología de la India. Se encontró que los datos simulados de precipitación y temperatura superficial están mejor representados en el CLM que en el BATS cuando se comparan con las observaciones. Más aún, se calculan varios parámetros estadísticos como el sesgo, el error cuadrático medio, el coeficiente de correlación espacial y niveles de aptitud (como el nivel equitativo de aptitud y la probabilidad de detección) para evaluar las simulaciones del RegCM utilizando ambos LSPS. Los resultados indican que el error cuadrático medio disminuye y el coeficiente de correlación espacial se incrementa con el uso del CLM en comparación con
\end{abstract}


el BATS. El nivel equitativo de aptitud y la probabilidad de detección también indican que el desempeño del modelo para simular la escala de la precipitación estacional es mejor con el CLM que con el BATS. En general, estos resultados sugieren que el desempeño del RegCM acoplado con el CLM mejora la aptitud del modelo para predecir la precipitación invernal (15 a 25\%) y la temperatura (10 a 20\%) en el Himalaya occidental.

\section{ABSTRACT}

Climate prediction over the Western Himalaya is a challenging task due to the highly variable altitude and orientation of orographic barriers. Surface characteristics also play a vital role in climate simulations and need appropriate representation in the models. In this study, two land surface parameterization schemes (LSPS), the Biosphere-Atmosphere Transfer Scheme (BATS) and the Common Land Model (CLM, version 3.5 ) in the regional climate model (RegCM, version 4) have been tested over the Himalayan region for nine distinct winter seasons in respect of seasonal precipitation (three years each for excess, normal and deficit). Reanalysis II data of the National Centers for Environmental Prediction (NCEP)/Department of Energy (DOE) have been used as initial and lateral boundary conditions for the RegCM model. In order to provide land surface boundary conditions in the RegCM model, geophysical parameters (10 min resolution) obtained from the United States Geophysical Survey were used. The performance of two LSPS (CLM and BATS) coupled with the RegCM is evaluated against gridded precipitation and surface temperature data sets from the India Meteorological Department (IMD). It is found that the simulated surface temperature and precipitation are better represented in the CLM scheme than in the BATS when compared with observations. Further, several statistical analysis such as bias, root mean square error (RMSE), spatial correlation coefficient (CC) and skill scores like the equitable threat score (ETS) and the probability of detection (POD) are estimated for evaluating RegCM simulations using both LSPS. Results indicate that the RMSE decreases and the CC increases with the use of the CLM compared to BATS. ETS and POD also indicate that the performance of the model is better with the CLM than with the BATS in simulating seasonal scale precipitation. Overall, results suggest that the performance of the RegCM coupled with the CLM scheme improves the model skill in predicting winter precipitation (by 15-25\%) and temperature (by 10-20\%) over the Western Himalaya.

Keywords: Western Himalaya, land surface schemes, regional climate model.

\section{Introduction}

The Western Himalayan region receives a substantial amount of precipitation in the form of snow during the winter months (December, January and February [DJF]). Precipitation over this region shows a large inter-annual variability and is vital for several sectors such as agriculture/horticulture, transportation, tourism, hydropower projects and water resources and management. Excess precipitation over this region causes landslides/avalanches and impacts livelihoods and infrastructure. Due to the complex orography, nonlinear interactions of land-atmosphere processes and insufficient observed datasets, seasonal-scale prediction of precipitation over such a heterogeneous region is one of the challenging tasks for meteorologists. Since the heterogeneity of the mountain region plays a dominant role in modulating the regional climate (Pielke et al., 1990; Dickinson, 1995), an advanced land surface parameterization scheme (LSPS) in a model may be able to improve the prediction skill over the mountain region.

Henderson-Sellers and Dickinson (1993) found in their study that more than $30 \%$ of the lower boundary conditions for the earth surface are provided through land-atmosphere interface in global climate models and in the case of regional climate modeling systems, this percentage can be even higher. Since the exchange of momentum and energy between land surface and the atmosphere affects prognostic variables such as surface temperature, precipitation, etc., a better representation of surface boundary conditions in a model is very important. Ding et al. (1998) examined the role of different land surface processes and found that the efficiency of a regional climate model (RCM) in the simulation of precipitation is increased when an improved land-surface parameterization scheme is used. A few studies have been carried out on the impact of different land LSPS in the simulation of upper air circulation associated with precipitation (Pielke et al., 2003; Singh et al., 2007; Dutta et al., 2009; Kar et al., 2014; Tiwari et al., 2014) over the Indian region. It was found that LSPS plays a crucial role in seasonal scale simulation over the Indian region. However, most of these studies have been conducted for the Indian summer monsoon season and so far there are no such studies for the 
winter season (DJF) examining the role of different LSPS in a RCM over the Western Himalayan region.

The main objective of the present study is to evaluate the performance of two LSPS, the Biosphere-Atmosphere Transfer Scheme (BATS) (Dickinson et al., 1993) and the Common Land Model (CLM), v. 3.5 (Oleson et al., 2008), in the Regional Climate Model (RegCM) v. 4 (Pal et al., 2007) to simulate winter precipitation and temperature over the Western Himalaya.

The remainder of this paper is organized as follows. A brief description of the model used, including characteristics and methodology of the simulation, is presented in sections 2 and 3, respectively. Section 4 describes the results and discusses the sensitivity experiments with BATS and CLM. Finally, salient features of the study are concluded in section 5 .

\section{Model description}

The dynamical core of the RegCM (v. 4) model is similar to the hydrostatic version of the mesoscale model MM5 (Grell et al., 1994). The RegCM standard model configuration consists of 18 vertical sigma levels in which five levels (at approximately 40, 110, 310,730 and $1400 \mathrm{~m}$ from surface) are in the lower troposphere (within $1.5 \mathrm{~km}$ from the surface [Giorgi and Bates, 1989]). The radiative transfer package of the NCAR Community Climate Model v. 3 (Kiehl et al., 1996), the mass flux cumulus cloud scheme of Grell (1993) with Fritch-Chappell closure (Fritsch and Chappell, 1980) and the nonlocal boundary scheme by Holtslag et al. (1999) are used in the Reg$\mathrm{CM}$. The land-surface processes are incorporated via the Biosphere-Atmosphere Transfer Scheme (BATS) (Dickinson et al., 1993) and the Community Land Model (CLM) (Oleson et al., 2008) schemes. For this study, the span of the model domain is $18-45^{\circ} \mathrm{N}$, $60-95^{\circ} \mathrm{E}$. The model domain and the orography shown in Figure 1 cover all parts of northwest India. A model grid with horizontal resolution of $30 \times 30 \mathrm{~km}$ is selected to conduct the simulation experiments. As can be seen from the figure, the maximum height of the Himalayas represented at this resolution is about $5500 \mathrm{~m}$. Most of the sharp gradient in the orography of the Himalayas gets smoothed out due to the resolution chosen for the model. Sinha et al. (2013) carried out a detailed study on the role of representation of orography in the RegCM3 simulations. A brief on model config-

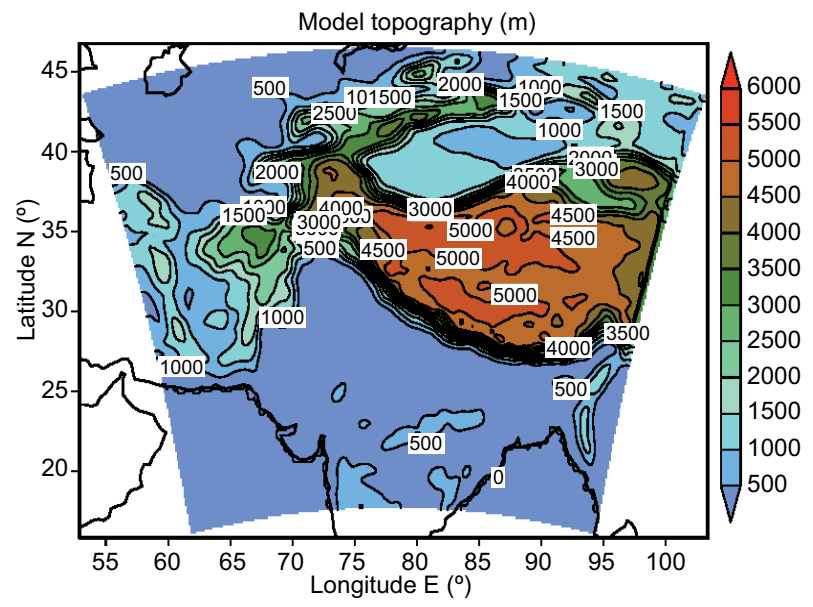

Fig. 1. The RegCM model domain used in the present study.

uration used in this study is also given in Table I. In this study, two sets of numerical experiments are carried out with different land surface models, BATS and CLM.

The BATS land surface parameterization scheme is used to describe the role of soil moisture and vegetation in the model. It calculates the exchanges of momentum, energy, and water vapor associated with surface-atmosphere interactions. It has one vegetation layer, a surface soil layer, a snow layer and 20 vegetation types. The prognostic equations for the soil layer temperatures are solved by using a generalized force-restore method (Dickinson et al., 1993). The CLM (Oleson et al., 2008) contains one vegetation layer with a canopy photosynthesis-conductance model, 10 unevenly spaced soil layers, five snow layers with an additional representation of trace snow, and 24 vegetation types. In this scheme, for each layer temperature, ice water and liquid water are solved explicitly. The CLM uses a mosaic approach for capturing land surface heterogeneity within a climate model at each grid cell. The main advantage of the CLM over BATS is that in the former, a higher number of soil layers and vegetation fractions are included. The CLM has the ability to include subgrid "tiles" with separate water and energy balance conducted for each tile. This approach enables the representation of various surface parameters (e.g., surface temperature, precipitation, fluxes, etc.) in a better way compared to BATS (Steiner et al., 2005). A brief comparison of these two land surface parameterization schemes is provided in Table II. 
Table I. Configuration of the RegCM4 used in the present study.

\begin{tabular}{ll}
\hline Dynamics & Hydrostatic \\
\hline Main prognostic variables & $u, v t, q$ and $p$ \\
\hline Model domain & $18-45^{\circ} \mathrm{N}, 60-95^{\circ} \mathrm{E}$; res. $=30 \mathrm{~km}$ \\
\hline Map projection & Lambert conformal mapping \\
\hline Vertical coordinate & $\begin{array}{l}\text { Terrain-following sigma coordinate } \\
\text { Total: 18 sigma levels (five levels in PBL) }\end{array}$ \\
\hline Cumulus parameterization & Grell with Fritch \& Chappell closure \\
\hline Land surface models & $\begin{array}{l}\text { Biosphere-Atmosphere Transfer Scheme (BATS) } \\
\text { and Community Land Model (CLM) }\end{array}$ \\
\hline Radiation parameterization & NCAR/CCM3 radiation scheme \\
\hline PBL parameterization & Holtslag \\
\hline
\end{tabular}

Table II. A brief comparison between two land surface parameterization schemes (i.e., BATS and CLM).

\begin{tabular}{lll}
\hline Category & BATS & CLM \\
\hline $\begin{array}{l}\text { Land cover/vegetation } \\
\text { classes }\end{array}$ & 20 vegetation types & 24 vegetation types \\
\hline Surface representation & $\begin{array}{l}\text { One vegetation layer, a surface soil layer, } \\
\text { a snow layer }\end{array}$ & $\begin{array}{l}\text { One vegetation layer with a canopy photosynthesis- } \\
\text { conductance model, 10 unevenly spaced soil } \\
\text { layers, five snow layers with an additional } \\
\text { representation of trace snow }\end{array}$ \\
\hline $\begin{array}{l}\text { Soil temperatures } \\
\text { calculation }\end{array}$ & Uses a two-layer force-restore model & $\begin{array}{l}\text { Soil temperature is calculated explicitly by a } \\
\text { 10-layer soil model }\end{array}$ \\
\hline $\begin{array}{l}\text { Treatment of vegetation } \\
\text { canopy }\end{array}$ & $\begin{array}{l}\text { Treats all vegetation } \\
\text { within the canopy in the same } \\
\text { manner }\end{array}$ & $\begin{array}{l}\text { The canopy is divided into sunlit and shaded } \\
\text { fractions as a function of LAI }\end{array}$ \\
\hline $\begin{array}{l}\text { Calculation of stomatal } \\
\text { conductance and } \\
\text { photosynthesis rate }\end{array}$ & $\begin{array}{l}\text { No individual calculation is made for } \\
\text { sunlit and shaded fractions. It does not } \\
\text { compute photosynthetic rates }\end{array}$ & $\begin{array}{l}\text { Stomatal conductance is calculated for sunlit and } \\
\text { shaded fractions. Calculation of photosynthetic } \\
\text { rates is done in this scheme }\end{array}$ \\
\hline $\begin{array}{l}\text { Treatment of heat and } \\
\text { roughness length }\end{array}$ & $\begin{array}{l}\text { Heat and water vapor roughness lengths } \\
\text { are constant }\end{array}$ & $\begin{array}{l}\text { Updates these values over bare soil and snow with } \\
\text { values from the stability functions }\end{array}$ \\
\hline $\begin{array}{l}\text { Albedo treatment } \\
\text { Uses prescribed values for vegetation } \\
\text { albedo for both short- and longwave } \\
\text { components }\end{array}$ & $\begin{array}{l}\text { Uses a modified two stream approach that reduces } \\
\text { the complexity of a full two-stream albedo } \\
\text { treatment }\end{array}$ \\
\hline
\end{tabular}

3. Simulation specifics and verification methodology

Seasonal (winter) precipitation anomalies over the Indian areas of the Western Himalayan region have been computed using 33 years (1975-2008) of observed precipitation data from the India Meteorological Department (IMD) (Rajeevan et al., 2006).
For the present study, extreme (excess or deficit) precipitation seasons are considered on the basis of precipitation anomaly departures by one standard deviation or more from its mean. Therefore, within these 33 years, there are three years in the category of excess precipitation (1990-1991, 1994-1995, 1997-1998, hereafter referred to as excess years); 
three years in the category of deficit precipitation (1996-1997, 2000-1901, 2004-1905, hereafter referred to as deficit years), and three years in the category of normal precipitation (1988-1989, 1993 1994, 2003-2004, hereafter referred to as normal years). In the present study, these years are considered to conduct the numerical experiments. Composite analyses have been carried out by computing the difference between excess minus normal and deficit minus normal precipitation years.

The RegCM model has been integrated from November 1 to February 28 (February 29 during the leap year) for each winter season. In this study, model integration output for the first month (i.e., November) is not analyzed as it is considered the model spin up time. For each year (excess, deficit and normal), the RegCM model is integrated twice with two different LSPS; first, coupled with BATS and then coupled with CLM, keeping unchanged all the other parameters of the model. Initial and lateral boundary conditions (LBCs) for the model integration are provided by the National Centers for Environmental Prediction-Department of Energy (NCEP-DOE) reanalysis II to drive the RegCM model, and the LBCs are updated every $6 \mathrm{~h}$. The prescribed sea surface temperature in the model is the National Oceanic and Atmospheric Administration Optimum Interpolation SST (NOAAOI-SST-v. 2) at a $1 \times 1^{\circ}$ resolution). The geophysical parameters are from the United States Geophysical Survey (USGS) at a 10' resolution). The model-simulated results are validated with the IMD gridded $(1 \times$ $1^{\circ}$ ) observed precipitation and surface air temperature (hereafter simply referred to as temperature) data sets. For comparison of the model data with observations, model simulated results are interpolated bilinearly to the grid points of the observed data.

Statistical analysis such as spatial correlation coefficient (CC), root mean square error (RMSE), probability of detection (POD), equitable threat score (ETS), etc., have been carried out between model and IMD data sets. The POD indicates what fraction of the observed "yes" events was correctly forecasted. It is defined as,

$P O D=\frac{H}{H+M}$

where $H$ and $M$ are hits and misses for each category, respectively. $P O D$ ranges from 0 to 1 with $P O D=1$ indicating perfect skill in prediction (i.e., $\mathrm{M}=0$ ).
ETS is a skill metric generally used for yes/no forecasting (Gilbert, 1884; Wilks, 1995); it is defined as:

$$
\begin{gathered}
E T S=\frac{H-H_{\lambda}}{\left(H+M+F-H_{\lambda}\right)}, \text { where } \\
H_{\lambda}=\frac{(H+M)(M+F)}{T}
\end{gathered}
$$

and $M, H$ and $F$ are the number of misses, hits and false alarms, respectively, for each category. Hits due to random chance are denoted by $H_{\lambda}$ and $T$ is the total number of events. ETS varies from -0.33 to 1 with $E T S=0$ indicating no skill and $E T S=1$ indicating perfect skill in prediction. Student's $t$-test is used for statistical significance of the anomaly $\mathrm{CC}$, where the critical value of $\mathrm{CC}$ is 0.27 at a $90 \%$ confidence level (CL).

\section{Results and discussion}

The composite analyses of observed gridded temperature and precipitation during the winter season for excess, deficit and normal precipitation years are presented in Figure 2. It is clearly seen from the figure that temperature is comparatively cooler during the excess years as compared to normal and deficit years over Jammu and Kashmir. It is also seen that the seasonal mean temperature is warmer by $1-2{ }^{\circ} \mathrm{C}$ during deficit years than in excess years over the Western Himalayan region. The range of seasonal mean precipitation during excess years is about 4.5 to $6.5 \mathrm{~mm}^{\text {day }}{ }^{-1}$ with a maximum of $6.5 \mathrm{~mm}$ day $^{-1}$ over Jammu and Kashmir, whereas during deficit years the seasonal precipitation range is about 1.5 to $2.5 \mathrm{~mm} \mathrm{day}^{-1}$, with a maximum of $2.5 \mathrm{~mm}^{\text {day }}{ }^{-1}$ over the same region. Therefore, it is noticed that excess precipitation years are comparatively cooler than deficit precipitation years over the Indian part of the Western Himalayan region. In the following three sub-sections, the results obtained from the simulation of RegCM model with two different LSPS are analyzed.

\subsection{Spatial distribution of surface air temperature} The simulated seasonal average (DJF) temperature from experiments with BATS and CLM within the RegCM for nine distinct precipitation years (three excess, three deficit and three normal) was examined. 
(a) (Comp_Temp)

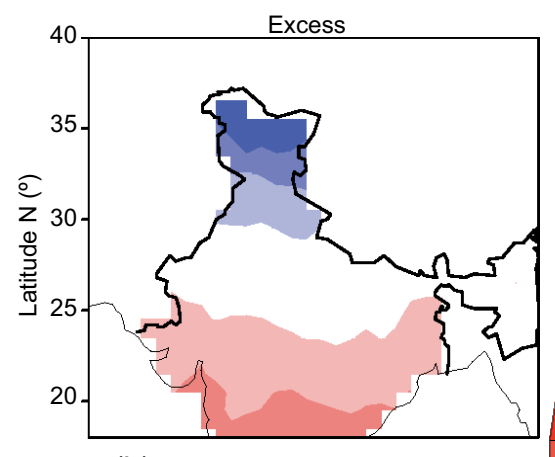

(b)

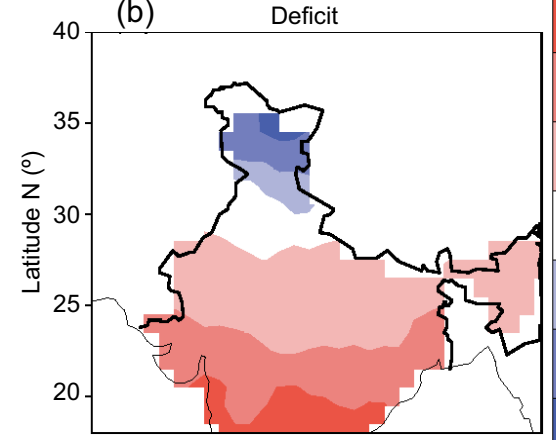

(c) Normal

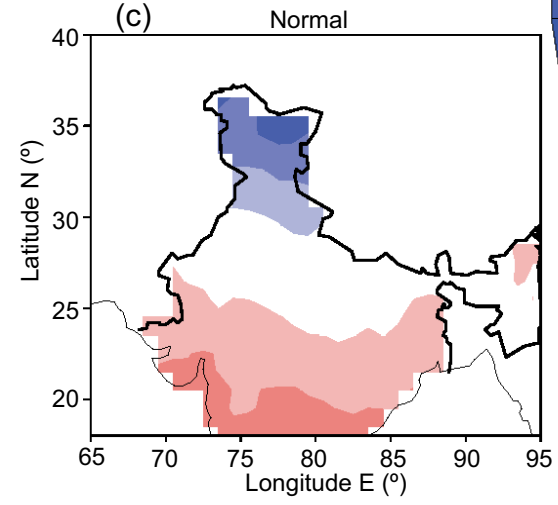

(d) (Comp_Precip)
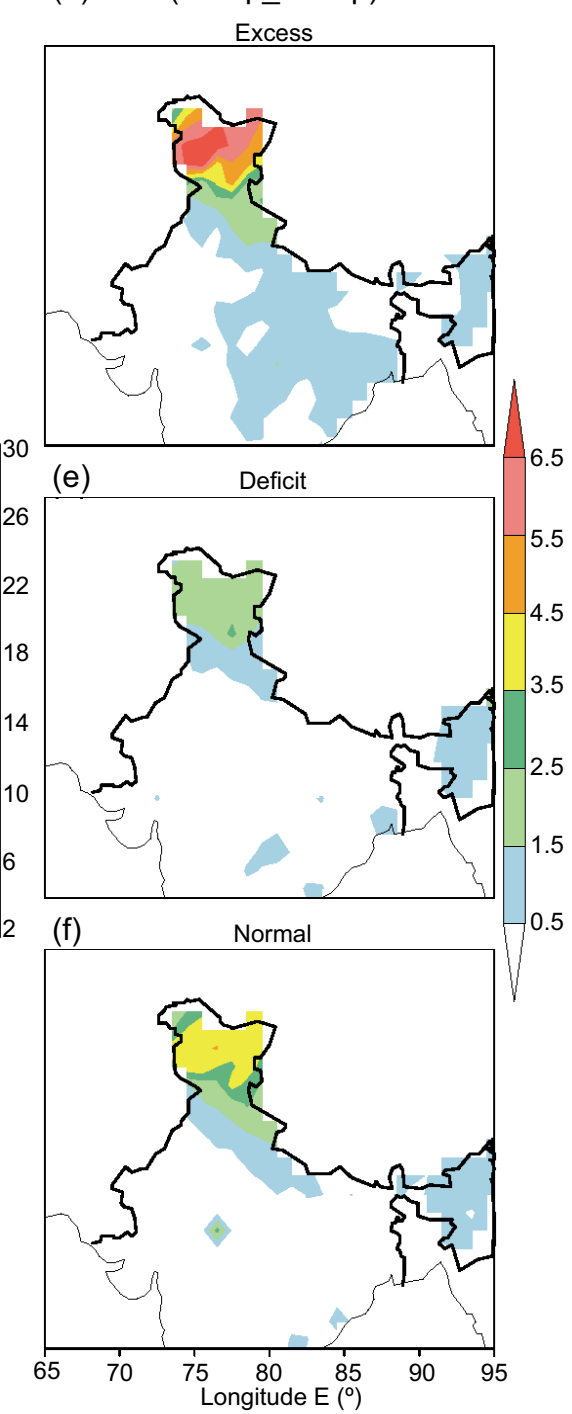

Fig. 2. Seasonal (DJF) average of IMD gridded temperature (in ${ }^{\circ} \mathrm{C}$ ) and precipitation (in mm day ${ }^{-1}$ ) for composite excess (a, d), composite deficit (b, e) and composite normal (c, f) precipitation years.

It was noticed that the model is able to reproduce the mean temperature distribution over the northwest India for the composite excess, composite deficit and composite normal years reasonably well when either of the land surface schemes (BATS or CLM) are used (figure not shown). However, the simulated temperature in terms of distribution and magnitude is better in the CLM experiment than in the BATS when results are compared against the observed surface temperature data sets.

In order to understand the variation of seasonal average winter temperature in distinct years, composite differences between excess and normal years, as well as between deficit and normal years are computed and shown in Figure 3. It can be seen from the figure that temperature is lower in the observations and in both RegCM simulation experiments in the excess years as compared to normal years. The left panel in Figure 3 shows that the RegCM model with BATS simulates a warmer surface by $1-2^{\circ} \mathrm{C}$ as compared to the CLM in the difference between composite excess and composite normal precipitation years. On the other hand, it is found that the area with cooler temperature is located more over the Western Himalaya 
(a)
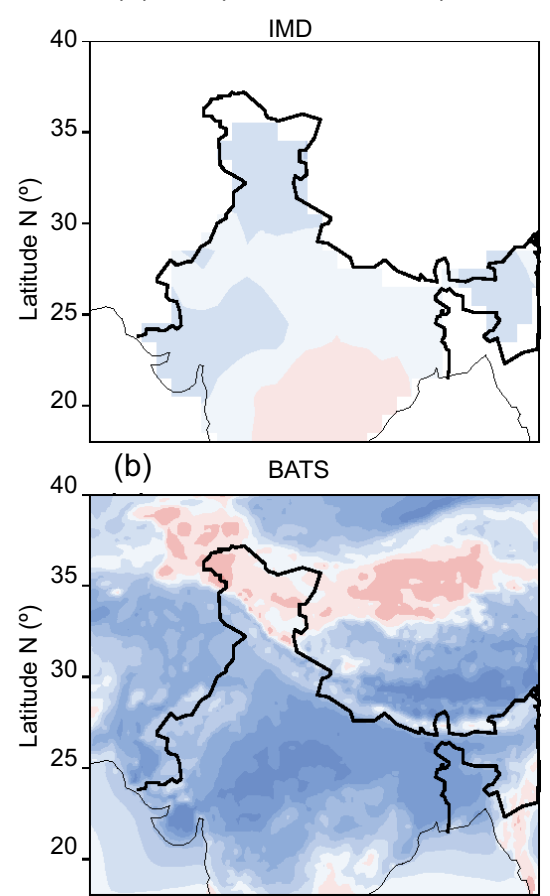

(c)

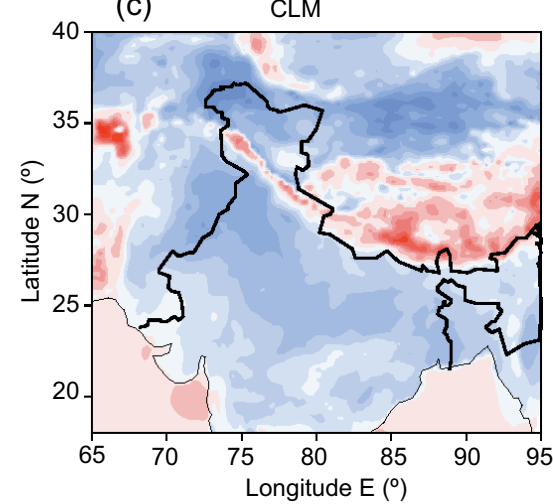

(d) (Deficit-Normal)

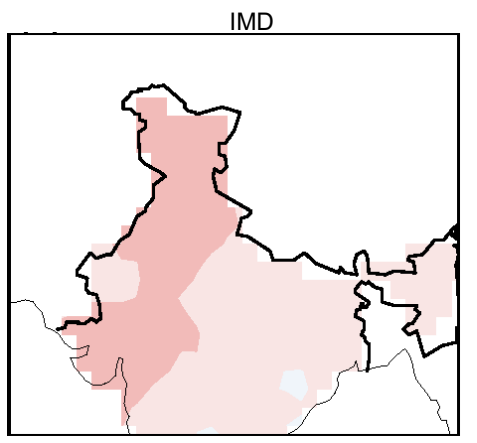

(e)

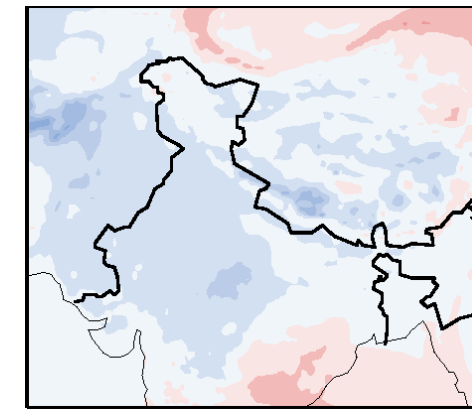

CLM

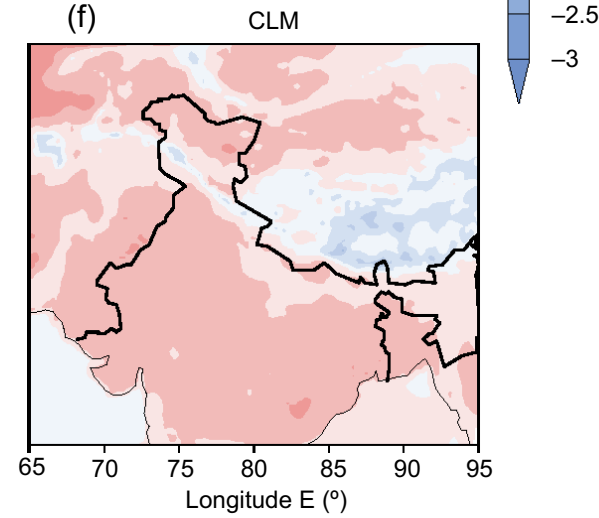

Fig. 3. Seasonal (DJF) difference of average surface air temperature (composite excess - composite normal and composite deficit - composite normal precipitation year) obtained from observed data (a, d) and RegCM4 model simulation with BATS $(\mathrm{b}, \mathrm{e})$ and CLM (c, f).

in the CLM than in the BATS. It can also be noticed that the magnitude and distribution of temperature differences between deficit and normal years with the CLM scheme is better than with the BATS when compared with the observed patterns (Fig. 3, right panel). The analysis reveals an improvement of $10-20 \%$ in the predictions of seasonal mean winter temperature with the use of CLM over BATS. So, the results suggest that the model-simulated mean as well as the variation in temperature (in terms of spatial distribution and magnitude) during the nine distinct years are better represented with the use of CLM as compared to BATS.

\subsection{Spatial distribution of precipitation}

The response of the BATS and CLM schemes in the RegCM model is examined in terms of precipitation simulations in the nine distinct years described earlier. Results indicate that the model is able to represent the seasonal mean precipitation distribution for the composites of excess, deficit and normal years reasonably well with both land surface schemes (figure 
(a)

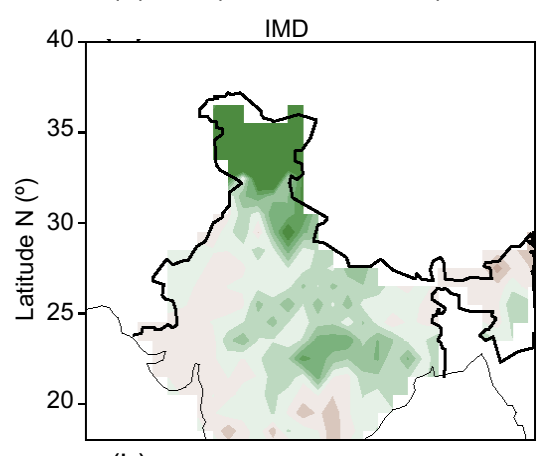

(b)

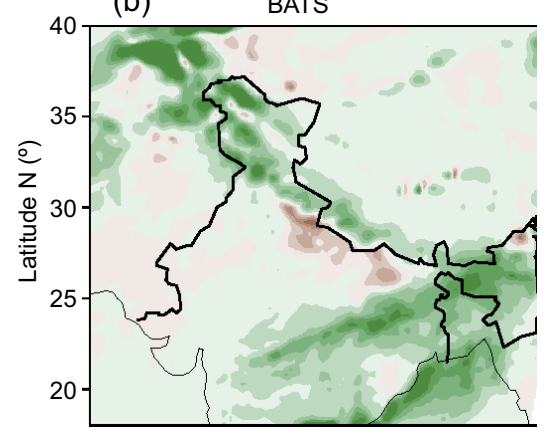

(c)

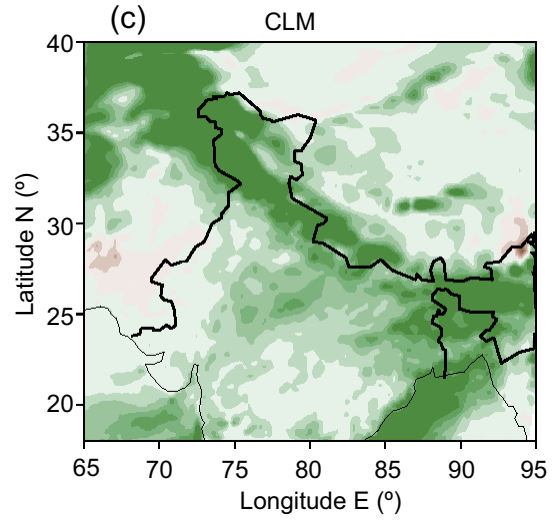

(d) (Deficit-Normal) IMD

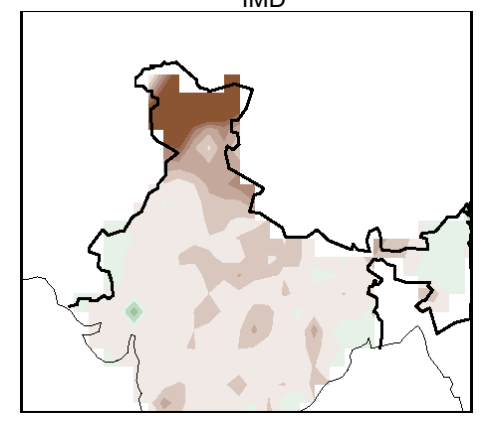

(e)

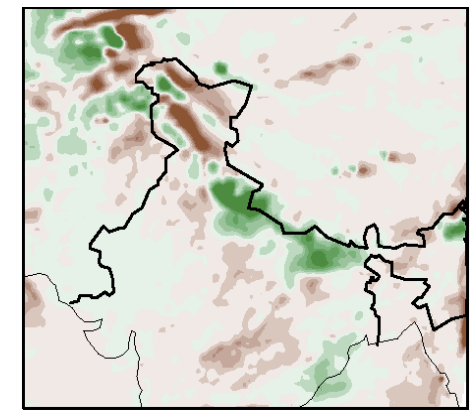

(f)

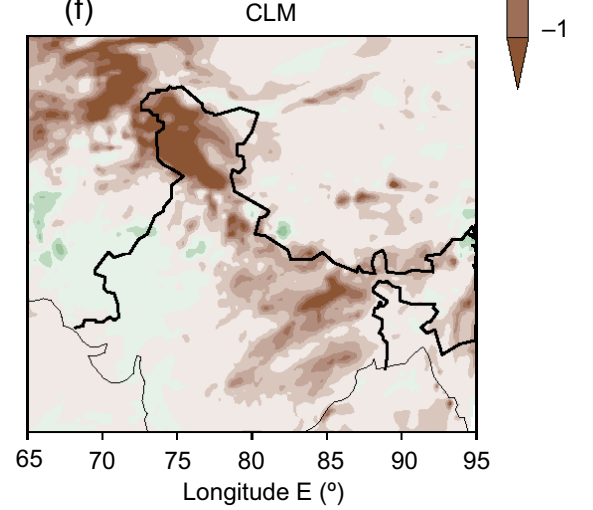

Fig. 4. Seasonal (DJF) difference of average precipitation (composite excess - composite normal and composite deficit - composite normal precipitation year) obtained from observed data (a, d) and RegCM4 model simulation with BATS (b, e) and CLM (c, f).

not shown). However, in terms of distribution and intensity the model-simulated precipitation is closer to observations with the use of the CLM scheme. To understand the RegCM model efficiency in simulating precipitation during the nine distinct years, the seasonal mean (DJF) composite precipitation differences between excess and normal years, as well as between deficit and normal years, are computed. Precipitation differences are shown in Figure 4. In the precipitation difference between excess and composite normal years (Fig. 4, left panel), it is seen that the representation of precipitation in terms of intensity and distribution is better with CLM than with BATS scheme when compared to observed differences. The precipitation differences between deficit and normal years (Fig. 4, right panel) are captured well in both LSPS (CLM and BATS) over northwest India, however, the variation in precipitation is closer to the observations with the CLM scheme than with BATS. The qualitative description of seasonal precipitation suggests that the efficiency of the RegCM model is higher with the CLM scheme than with BATS.

The area average of monthly as well as seasonal composite precipitation obtained from the IMD 

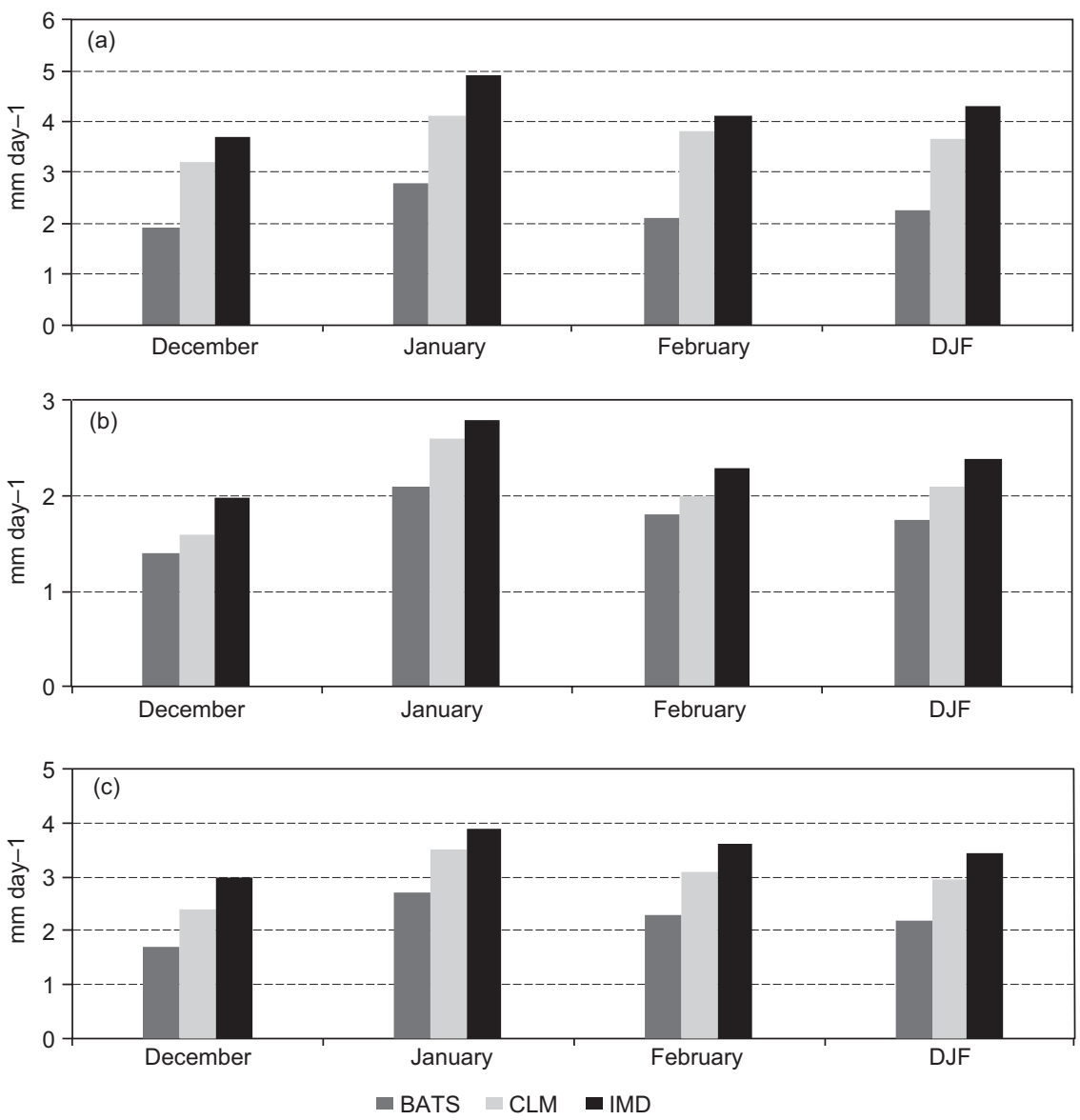

Fig. 5. Monthly and seasonal average precipitation $\left(\mathrm{mm} \mathrm{day}^{-1}\right)$ from IMD gridded precipitation, and RegCM4 model simulation with BATS and CLM, for (a) composite excess, (b) composite deficit and (c) composite normal precipitation year.

observations and the RegCM (with BATS and CLM) simulations were computed and are exhibited in Figure 5, which shows that the area-averaged precipitation is underestimated in both LSPS during all of the years (composite of excess, composite of deficit and composite of normal years, respectively) at monthly as well as seasonal scale. However, the RegCM simulations with CLM are closer to observations. An improvement in the precipitation magnitude by about $15-25 \%$ is noticed with the CLM scheme over BATS in the seasonal mean simulations. It may be noticed that the improvement varies from year to year. During all the months and seasons, the efficiency of the RegCM model is higher when run with CLM instead of BATS, though the rate of improvement is higher in January than in other months. The better simulation of precipitation with CLM as compared to BATS may be due to the inclusion of more number of soil layers and a better representation of the vegetation cover in the former, as described below.

The vegetation cover over the region of interest as used by both LSPS (BATS and CLM) is shown in Figure 6. It can be seen from the diagram that vegetation cover in the RegCM-CLM simulations has a greater spatial coverage over the Indian part of the Western Himalaya than the RegCM-BATS. This increased vegetation cover in the RegCM-CLM enhances precipitation as found in Zheng et al. (2002).

Soil moisture from the NCEP-DOE reanalysis II and the RegCM simulations (with BATS/CLM LSPS) are shown in Figure 7 for the composites of excess and normal years, and deficit and normal precipitation years. Observations show positive soil moisture over northern India, which is well brought out by both LSPS. However, the spatial extent is lower in the RegCM-BATS simulation for the composite of excess minus normal years. In the case of 


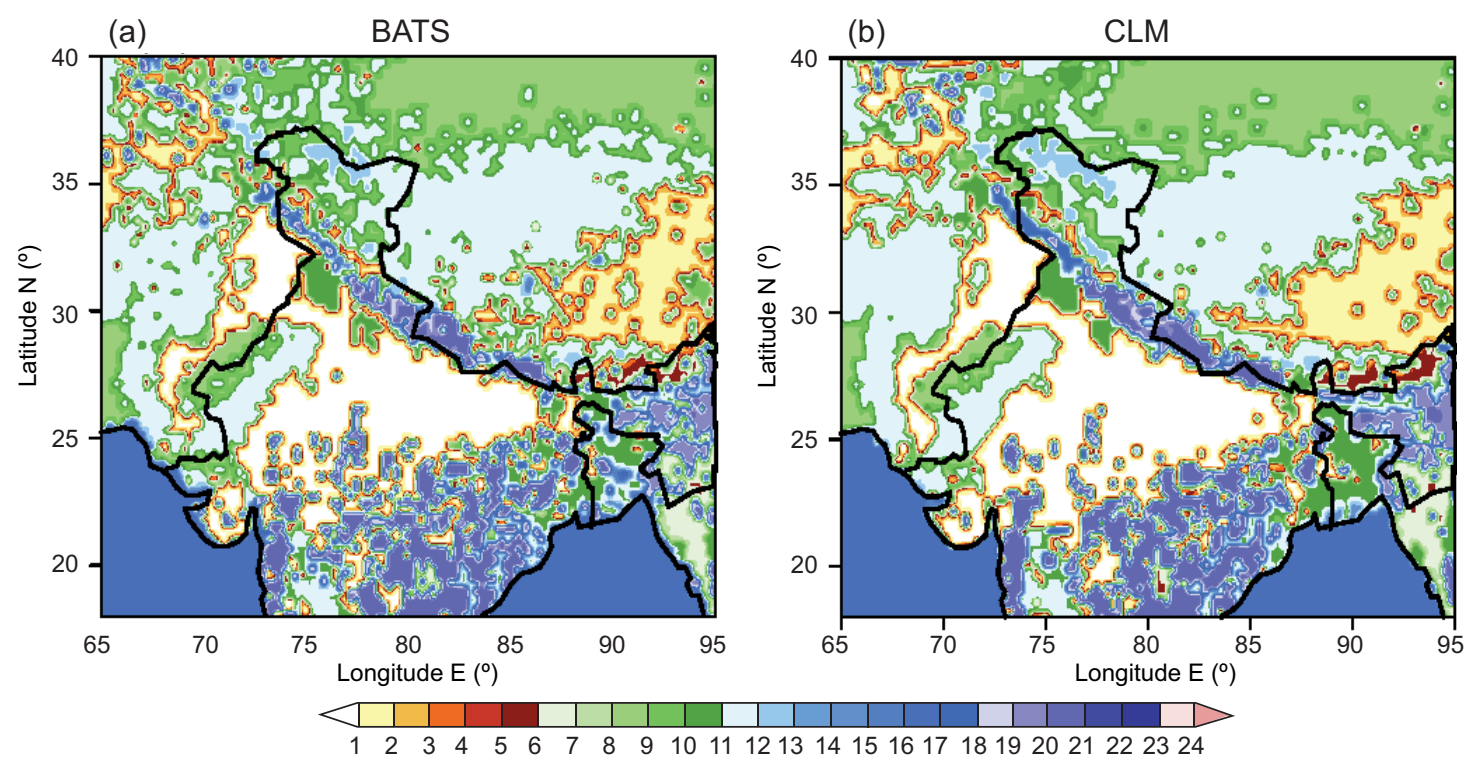

Fig. 6. Vegetation cover in (a) BATS and (b) CLM land surface schemes.

the composite difference between deficit and normal precipitation years, the spatial extent and intensity is closer to observations with the RegCM-CLM as compared to the RegCM-BATS simulation. This difference in model simulation is due to the difference in soil descriptions and moisture representations between these two LSPS. Therefore, the better representation of soil moisture may be the reason for a better representation of precipitation in the RegCM-CLM simulation.

Sensible heat fluxes from the NCEP-DOE reanalysis II and the RegCM simulations (with BATS/ CLM LSPS) are depicted in Figure 8 for composites of excess minus normal and deficit minus normal precipitation years. The composite analysis between excess minus normal precipitation years indicates that both LSPS show almost similar spatial extents of precipitation over the eastern parts of Jammu and Kashmir. However, over the western part of Jammu and Kashmir, the RegCM-CLM simulation produces more wet zones as compared to the RegCM-BATS simulation. In the case of composite differences between deficit and normal precipitation years, simulations with both land surface schemes are mostly similar.

\subsection{Statistical evaluation of precipitation}

The performance of the RegCM model with the BATS and CLM land surface schemes has been evaluated by computing various statistical skill scores. Some important evaluation strategies consisted in estimating the RMSE and the CC, between others. The model skill scores were estimated against observed gridded precipitation data from the IMD over the Indian part of the Western Himalaya. The model results are bi-linearly interpolated to the grid points of the IMD observed data for statistical evaluation. The RMSE and spatial CC are calculated for both sets of runs using CLM and BATS (Table III). It can be seen that the CC is statistically significant (the threshold value is 0.27 at a $90 \%$ confidence level) in the precipitation simulation with the CLM scheme during excess, deficit and normal precipitation years. The $\mathrm{CC}$ is higher in the CLM experiment $(0.39,0.35$ and 0.37 , respectively) than in the BATS experiment for all the years in which simulations were carried out within this study. The RMSE values of the RegCM model are lower when the CLM scheme is used in comparison with BATS. This suggests that the spatial distribution of precipitation and its intensity are simulated better in the RegCM with the CLM scheme than with BATS.

Several other skill metrics, such as POD, accuracy, ETS, and bias have been estimated for the distinct precipitation years and presented in Table IV. When the observed precipitation is higher than or equal to $1 \mathrm{~mm} \mathrm{day}^{-1}$, that day is considered as a wet day. It can be seen from the statistical 
(a) (Excess-Normal)

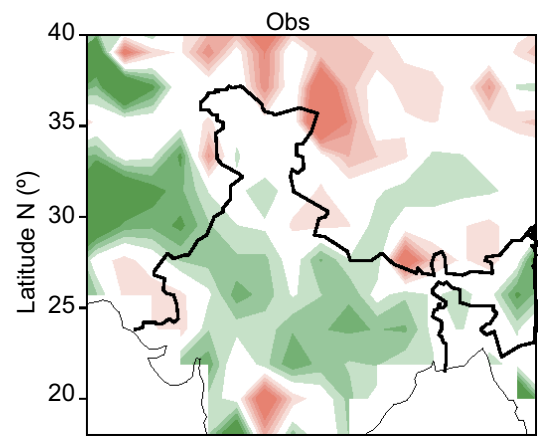

(b)

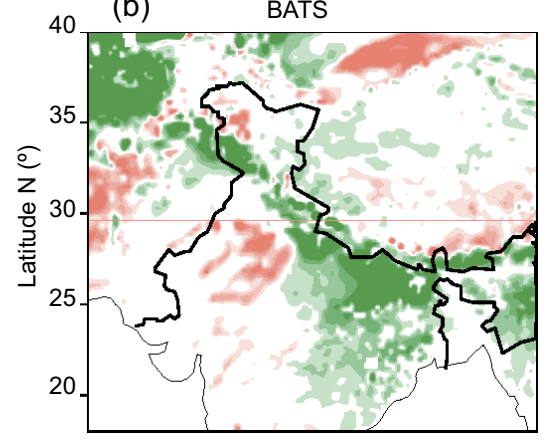

(c)

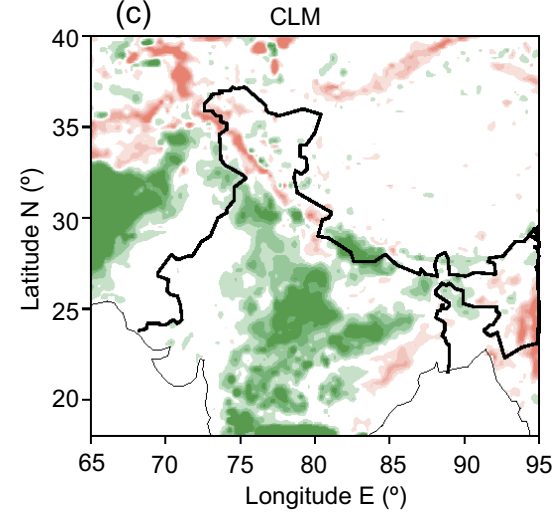

(d) (Deficit-Normal)

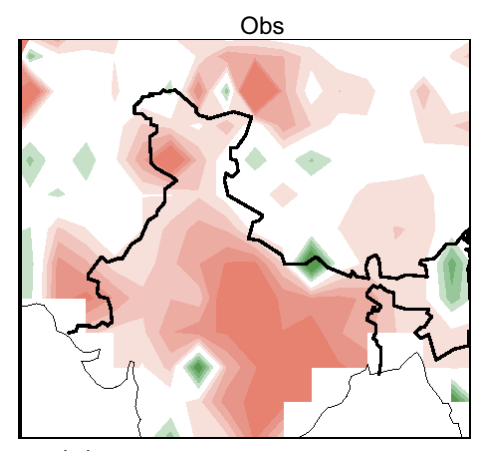

(e)
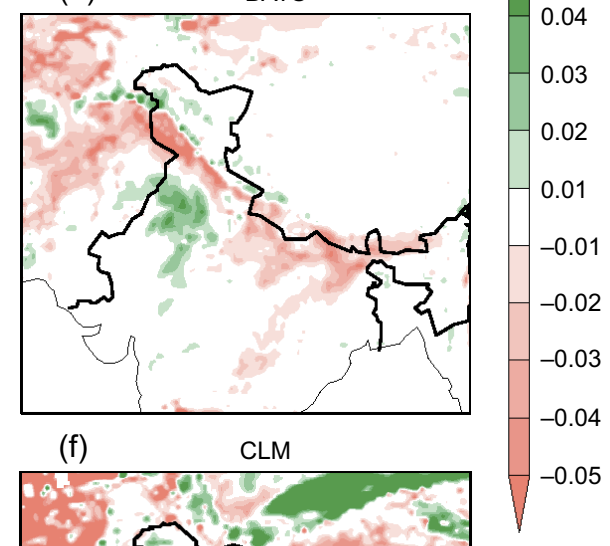

Fig. 7. Seasonal (DJF) soil moisture ( $\mathrm{kg} / \mathrm{kg}$ ) difference (composite excess - composite normal and composite deficit - composite normal precipitation year) obtained from observed data (a, d) and RegCM4 model simulation with BATS (b, e) and CLM (c, f).

analysis that POD values are higher in the CLM experiment $(0.75,0.70$ and 0.88 for the excess, deficit and normal years, respectively) than in the BATS experiment for all the three distinct years. It is also found that the number of wet days simulated in the CLM experiment is closer to observations. Furthermore, the accuracy of precipitation simulations is higher with CLM than with BATS over the Western Himalaya. The computed model bias indicates that the precipitation intensity and distribution is better represented with the CLM (bias is closer to 1). However, the model-simulated precipitation is underestimated with respect to observations in both schemes. Table IV indicates that ETS is higher in the CLM simulations during all the years, which indicates that precipitation events are better represented with the CLM land surface scheme.

Thus, the statistical analysis (forecast errors and skill scores) also reveals that the RegCM model with the CLM parameterization scheme performs better in simulating precipitation for extreme years with reasonable accuracy over the Western Himalayan region, as compared to the RegCM with BATS. 
(a) (Excess-Normal)

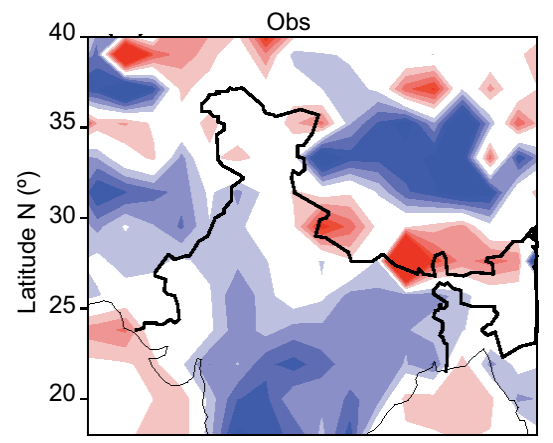

(b)

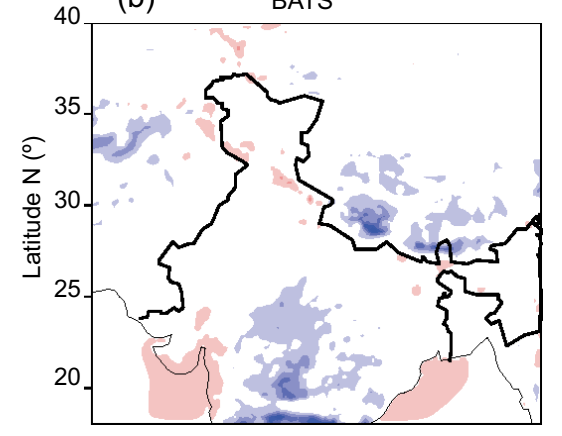

(c)

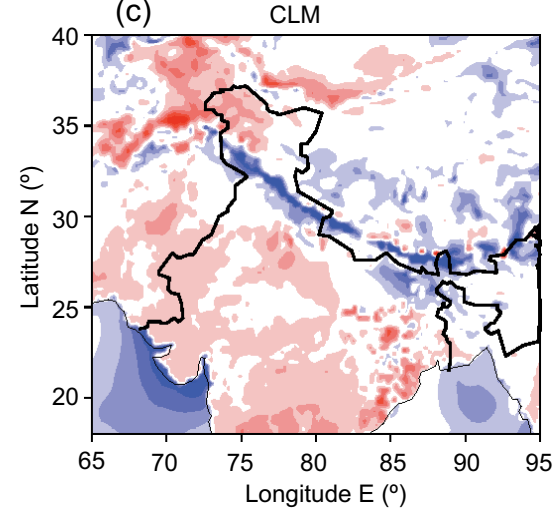

(d) (Deficit-Normal)

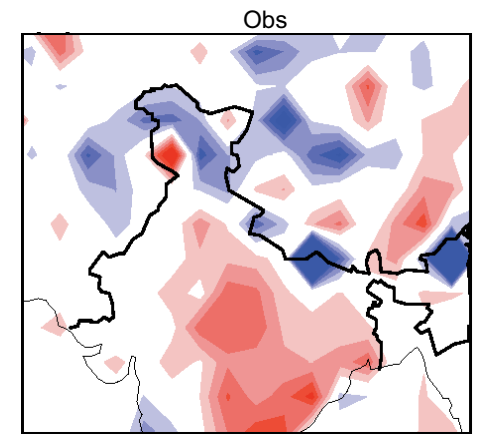

(e)
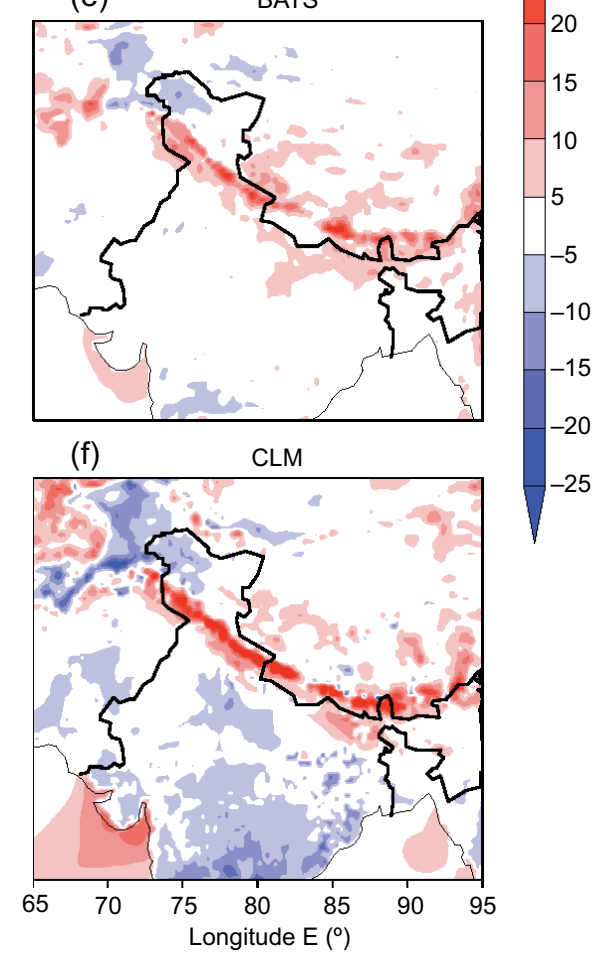

Fig. 8. Seasonal (DJF) sensible heat flux $\left(\mathrm{W} \mathrm{m}^{-2}\right)$ difference (composite excess - composite normal and composite deficit - composite normal precipitation year) obtained from observed (a, d) and RegCM4 model simulation with BATS (b, e) and CLM (c, f).

Table III. RMSE and CC for excess, deficit and normal precipitation years.

\begin{tabular}{lcccc}
\hline & & Excess & Deficit & Normal \\
\hline RMSE & BATS & 3.448 & 1.587 & 2.778 \\
& CLM & 3.312 & 1.385 & 2.529 \\
CC & BATS & 0.359 & 0.313 & 0.351 \\
& CLM & 0.385 & 0.352 & 0.374 \\
\hline
\end{tabular}

RMSE: root mean square error; $\mathrm{CC}$ : correlation coefficient.

\section{Conclusion}

In the present study we compared two different land surface parameterization schemes within the RegCM, i.e. BATS and CLM, to simulate nine distinct winter precipitation years over the Western Himalaya. During the winter months, a notable difference between the BATS and CLM experiments is observed in the simulation of temperature and amount of precipitation. The performance of the RegCM with both LSPS is reasonable in reproducing the mean features of seasonal temperature and precipitation, however the skill of the model is higher with the 
Table IV. Skill score for excess, deficit and normal precipitation years for the $>1 \mathrm{~mm}$ rainfall category.

\begin{tabular}{lccccc}
\hline Year & Land surface scheme & POD 1 (0 to 1) & Accuracy 1 (0 to 1) & Bias 1 (0 to $\infty)$ & ETS 1 (-1/3 to 1) \\
\hline Excess & BATS & 0.715 & 0.589 & 1.502 & 0.113 \\
& CLM & 0.747 & 0.596 & 1.642 & 0.182 \\
Deficit & BATS & 0.693 & 0.633 & 1.952 & 0.071 \\
\multirow{2}{*}{ Normal } & CLM & 0.697 & 0.711 & 1.381 & 0.167 \\
& BATS & 0.852 & 0.656 & 1.458 & 0.179 \\
& CLM & 0.876 & 0.683 & 1.229 & 0.187 \\
\hline
\end{tabular}

CLM scheme. Furthermore, temperature and precipitation during extreme winter seasons are also better captured with the CLM scheme than with BATS when compared to observations. As mentioned earlier, most of the sharp gradient in the orography of the Himalayas gets smoothed due to the resolution chosen for the model. Similarly, the surface characteristics (soil type, soil wetness, vegetation cover, etc.) are not properly represented in the model due to the chosen resolution, as there is a sharp gradient in these parameters over the Himalayan region. This study suggests that even at this resolution, the RegCM model with CLM and BATS is able to reproduce some of the salient features of the distinct years examined.

Forecast errors and skill scores indicate that the performance of the RegCM model is better with the CLM scheme rather than with BATS. Moreover, improvements by about $10-20 \%$ in temperature and 15 $25 \%$ in precipitation predictions are observed with the use of the CLM scheme in comparison with BATS. In sum, the study indicates that the RegCM model with the CLM scheme can be more informative in simulating wintertime temperature and precipitation over the Western Himalayan region.

\section{Acknowledgments}

The authors acknowledge the support of the Snow and Avalanche Study Establishment (SASE) for carrying out this study. The RegCM4 installed at IIT Delhi was developed at the Abdus Salam ICTP, Trieste, Italy and is duly acknowledged. The authors also acknowledge the India Meteorological Department for providing valuable data sets for the accomplishment of this work. The authors also duly acknowledge the NCEP for reanalysis II data and the NOAA for optimum interpolated SST, v. 2 (NOAA_OI_SST_V2) data provided by the NOAA/ OAR/ESRL PSD, Boulder, Colorado, USA, from their web site at http://www.esrl.noaa.gov/psd/. Authors also wish to thank two anonymous reviewers for their constructive suggestions that improved the manuscript significantly.

\section{References}

Dickinson R. E., A. Henderson-Sellers and P. J. Kennedy, 1993. Biosphere-atmosphere transfer scheme (BATS) version $1 \mathrm{e}$ as coupled to the NCAR Community Climate Model. NCAR Technical Note NCAR/TN387+STR, 72 pp., doi:10.5065/D67W6959.

Dickinson R. E., 1995. Land-atmosphere interaction. Rev. Geophys. 33, 917-922.

Ding Y., J. Zhang and Z. Zhao, 1998. An improved land-surface processes model and its simulation experiment. 2. Land-surface process model (LPM-ZD) and its coupled simulation experiment with regional climate model. Acta. Meteorol. Sin. 56, 385-400.

Dutta S. K., S. Das, S. C. Kar, U. C. Mohanty and P. C. Joshi, 2009. Impact of vegetation on the simulation of seasonal monsoon rainfall over the Indian subcontinent using a regional model. J. Earth Syst. Sci. 118, 413-440.

Fritsch J. M. and C. F. Chappell, 1980. Numerical prediction of convectively driven mesoscale pressure systems, part 1: Convective parameterization. J. Atmos. Sci. 37, 1722-1733.

Gilbert G. K., 1884. Finley's tornado predictions. Am. Meteorol. J. 1, 166-172.

Giorgi F. and G. T. Bates, 1989. On the climatological skill of a regional model over complex terrain. Mon. Wea. Rev. 117, 2325-2347.

Grell G. A., 1993. Prognostic evaluation of assumptions used by cumulus parameterization. Mon. Wea. Rev. 121, 764-787.

Grell G. A., J. Dudhia and D. R. Stauffer, 1994. Description of the fifth generation Penn State/NCAR Mesoscale Model (MM5). NCAR Technical Note NCAR/TN398+STR, doi:10.5065/D60Z716B, 121 pp. 
Henderson-Sellers A. and R. E. Dickinson, 1993. Atmospheric-land surface fluxes. John Wiley and Sons, pp. 387-405.

Holtslag A. A. M., E. I. F. de Bruijn and H. L. Pan, 1999. A high resolution air mass transformation model for short-range weather forecasting. Mon. Wea. Rev. 118, 1561-1575.

Kar S. C., P. Mali and A. Routray, 2014. Impact of land surface processes on the South Asian monsoon simulations using WRF modeling system. Pure Appl. Geophys. 171, 2461-2484.

Kiehl J. T., J. J. Hack, G. B. Bonan, B. A. Boville, B. P. Briegleb, D. L. Williamson and P. J. Rasch, 1996. Description of the NCAR Community Climate Model (CCM3). NCAR Tech. Note NCAR/TN- 420+STR, $152 \mathrm{pp}$.

Oleson K. W., G. Y. Niu, Z. L. Yang, D. M. Lawrence, P. E. Thornton, P. J. Lawrence, R. Stockli, R. E. Dickinson, G. B. Bonan, S. Levis, A. Dai and T. Qian, 2008. Improvements to the Community Land Model and their impact on the hydrological cycle. J. Geophys. Res. 113, 1021-1026.

Pal J. S., F. Giorgi, X. Bi, N. Elguindi, F. Solmon, X. Gao, S. A. Rauscher, R. Francisco, A. Zakey, J. Winter, M. Ashfaq, F. Syed, S. Faisal. J. L. Bell, N. S. Diffenbaugh, J. Karmacharaya, A. Konare, D. Martinez, R. P. Da Rocha, L. C. Sloan and A. L. Steiner, 2007. Regional climate modeling for the developing world: The ICTP RegCM3 and RegCNET. Bull. Amer. Meteor. Soc. 88, 1395-1409.

Pielke R. A. and R. Avissar, 1990. Influence of landscape structure on local and regional climate. Landscape Ecol. 4, 133-155.
Pielke R. A., D. D. S. Niyogi, T. N. Chase and J. L. Eastman, 2003. A new perspective on climate change and variability: A focus of India. Proc. Indian Nat. Acad. Sci. 69, 585-602.

Rajeevan M., J. Bhate, J. Kale and B. Lal, 2006. High resolution daily gridded rainfall data for the Indian region: analysis of break and active monsoon spells. Curr. Sci. 91, 296-306.

Singh A. P., U. C. Mohanty, P. Sinha and M. Mandal, 2007. Influence of different land surface processes on Indian summer monsoon circulation. Nat. Hazards 42, 423-438.

Sinha P., U. C. Mohanty, S. C. Kar and S. Kumari, 2014. Role of the Himalayan orography in simulation of the Indian summer monsoon using RegCM3. Pure Appl. Geophys. 171, 1385-1407.

Steiner A. L., J. S. Pal, F. Giorgi, R. E. Dickinson and W. L. Chameides, 2005. A coupling of common land model (CLM0) to a regional climate model (RegCM). Theor. Appl. Climatol. 82, 225-243.

Tiwari P. R., S. C. Kar, U. C. Mohanty, S. Dey, P. Sinha, P.V.S. Raju and M. S. Shekhar, 2014. Dynamical downscaling approach for wintertime seasonal scale simulation over the Western Himalayas. Acta Geophysica. 62, 930-952.

Wilks, D.S., 1995. Statistical methods in the atmospheric sciences. Academic Press, San Diego, 467 pp.

Zheng Y., Yongfu Qian, Manqian Miao, Ge Yu, Yushou Kong and Donghua Zhang, 2002. The effects of vegetation change on regional climate I: Simulation results. Acta Meteorologica Sinica 60, 1-16. 